\title{
Cardiopulmonary resuscitation quality and beyond: the need to improve real-time feedback and physiologic monitoring
}

Steve $\operatorname{Lin}^{1,2,3^{*}}$ and Damon C. Scales ${ }^{3,4,5}$

See related research by Vahedian-Azimi, et al., http://ccforum.biomedcentral.com/articles/10.1186/s13054-016-1296-3

\begin{abstract}
High-quality cardiopulmonary resuscitation (CPR) has been shown to improve survival outcomes after cardiac arrest. The current standard in studies evaluating CPR quality is to measure CPR process measures-for example, chest compression rate, depth, and fraction. Published studies evaluating CPR feedback devices have yielded mixed results. Newer approaches that seek to optimize CPR by measuring physiological endpoints during the resuscitation may lead to individualized patient care and improved patient outcomes.

Keywords: Randomized controlled trial, Cardiopulmonary resuscitation, Feedback, End-tidal carbon dioxide, Near-infrared spectroscopy
\end{abstract}

\section{Background}

Vahedian-Azimi et al. [1] conducted the first in-hospital randomized controlled trial (RCT) evaluating a new cardiopulmonary resuscitation (CPR) feedback device-the Cardio First Angel-in cardiac arrest patients. Highquality CPR has been shown to improve survival outcomes after cardiac arrest [2] and continues to be a focus of quality assurance and improvement programs. There are multiple feedback devices that are commercially available to improve the quality of delivered CPR, but evaluations have yielded mixed results in published RCTs and observational studies [3-6]. Appropriately, international resuscitation guidelines do not currently

\footnotetext{
* Correspondence: LinS@smh.ca

${ }^{1}$ Rescu, Li Ka Shing Knowledge Institute of St. Michael's Hospital, Toronto, Ontario, Canada

${ }^{2}$ Division of Emergency Medicine, Department of Medicine, University of Toronto, Toronto, Ontario, Canada

Full list of author information is available at the end of the article
}

recommend implementing CPR feedback devices for clinical practice in isolation but rather as part of a comprehensive system of care for cardiac arrest $[5,6]$.

\section{Main text}

There are several important CPR process measures that currently define high-quality CPR: compression rate (100-120/minute), compression depth $(5-6 \mathrm{~cm}$ in adults), allowing for complete chest recoil after each compression, and minimizing interruptions in compressions measured by chest compression fraction $[5,6]$. These quantitative CPR process measures have been the most common targets of prior evaluations of CPR [3, 4]. Vahedian-Azimi et al. [1] instead developed two checklists to evaluate CPR: an effectiveness score (ranging from 0 to 10) and a guideline adherence score (ranging from 0 to 10). These scores assessed several aspects of CPR quality but a limitation is that assessors were unblinded to treatment allocation, increasing the potential for measurement bias. Overall, the new device improved both measures of CPR quality. The generalizability of these findings is also uncertain, especially considering that rates of cardiac arrest were markedly higher (approximately $35 \%$ ) than is typically expected among patients admitted to ICUs in other regions [7].

Chest compressions guided by CPR feedback devices to ensure adequate rate and depth are important [8]; however, their effect on patient physiology remains unclear. Indeed, current resuscitation guidelines use a "one size fits all" strategy, recommending the same compression rate and depth for all patients. Newer approaches to measuring physiology in real time during CPR may improve our ability to evaluate the quality of resuscitation in the future. Physiologic monitoring, specifically cardiac output and coronary and cerebral perfusion during resuscitation, are likely to be more sensitive to small changes that may guide resuscitative efforts, and at least 
in some studies have been correlated with improved clinical outcomes $[9,10]$. However, these measurements are difficult to obtain during real-life cardiac arrest resuscitation, particularly in the out-of-hospital setting. Another area of active investigation is the use of end-tidal carbon dioxide $\left(\mathrm{ETCO}_{2}\right)$ measurements, which are an indirect correlate of cardiac output and are readily available to rescuers performing CPR in cardiac arrest patients; however, as yet there are no recommended $\mathrm{ETCO}_{2}$ target values for $\mathrm{CPR}$, and their relationship with survival remains unclear [11]. There is even less evidence for other physiologic measurements; for example, near-infrared spectroscopy to measure cerebral oximetry [12-15].

\section{Conclusion}

As the ability to monitor physiology during cardiac arrest resuscitation improves, we should be able to individualize patient care by performing goal-directed CPR with the ultimate goal of improving patient survival and functional outcomes. This will require focused research into the effectiveness of goal-directed CPR using physiologic monitoring compared to current CPR standards.

\section{Abbreviations}

$\mathrm{CPR}$, cardiopulmonary resuscitation; $\mathrm{ETCO}_{2}$, end-tidal carbon dioxide; $\mathrm{RCT}$ randomized controlled trial.

\section{Authors' contributions}

Both SL and DCS made substantial contributions to drafting the manuscript. Both authors gave final approval of the version to be published.

\section{Competing interests}

$S L$ received operating grant funding from the ZOLL Foundation. DCS

declares that he has no competing interests.

\section{Author details}

${ }^{1}$ Rescu, Li Ka Shing Knowledge Institute of St. Michael's Hospital, Toronto, Ontario, Canada. ${ }^{2}$ Division of Emergency Medicine, Department of Medicine, University of Toronto, Toronto, Ontario, Canada. ${ }^{3}$ Institute of Health Policy, Management and Evaluation, University of Toronto, Toronto, Ontario, Canada. ${ }^{4}$ Department of Critical Care Medicine, Sunnybrook Health Sciences Centre, Toronto, Ontario, Canada. ${ }^{5}$ Interdepartmental Division of Critical Care Medicine, University of Toronto, Toronto, Ontario, Canada.

Published online: 28 June 2016

\section{References}

1. Vahedian-Azimi A, Hajiesmaeili M, Amirsavadkouhi A, et al. Effect of the Cardio First Angel ${ }^{\mathrm{TM}}$ device on CPR indices: a randomized controlled clinical trial. Crit Care. 2016;20:147.

2. Kleinman ME, Brennan EE, Goldberger ZD, et al. Part 5: Adult Basic Life Support and Cardiopulmonary Resuscitation Quality: 2015 American Heart Association Guidelines Update for Cardiopulmonary Resuscitation and Emergency Cardiovascular Care. Circulation. 2015;132:S414-35.

3. Hostler D, Everson-Stewart S, Rea TD, et al. Effect of real-time feedback during cardiopulmonary resuscitation outside hospital: prospective, clusterrandomised trial. BMJ. 2011;342:d512.

4. Bohn A, Weber TP, Wecker S, et al. The addition of voice prompts to audiovisual feedback and debriefing does not modify CPR quality or outcomes in out of hospital cardiac arrest-a prospective, randomized trial. Resuscitation. 2011;82:257-62.

5. Perkins GD, Travers AH, Berg RA, et al. Part 3: Adult basic life support and automated external defibrillation: 2015 International Consensus on
Cardiopulmonary Resuscitation and Emergency Cardiovascular Care Science with Treatment Recommendations. Resuscitation. 2015;95:e43-69.

6. Travers AH, Perkins GD, Berg RA, et al. Part 3: Adult Basic Life Support and Automated External Defibrillation: 2015 International Consensus on Cardiopulmonary Resuscitation and Emergency Cardiovascular Care Science with Treatment Recommendations. Circulation. 2015;132:S51-83.

7. Efendijev I, Nurmi J, Castren M, Skrifvars MB. Incidence and outcome from adult cardiac arrest occurring in the intensive care unit: a systematic review of the literature. Resuscitation. 2014:85:472-9.

8. Wallace SK, Abella BS, Becker LB. Quantifying the effect of cardiopulmonary resuscitation quality on cardiac arrest outcome: a systematic review and meta-analysis. Circ Cardiovasc Qual Outcomes. 2013;6:148-56.

9. Hartmann SM, Farris RW, Di Gennaro JL, Roberts JS. Systematic review and meta-analysis of end-tidal carbon dioxide values associated with return of spontaneous circulation during cardiopulmonary resuscitation. J Intensive Care Med. 2015;30:426-35.

10. Sanfilippo F, Serena G, Corredor C, et al. Cerebral oximetry and return of spontaneous circulation after cardiac arrest: a systematic review and metaanalysis. Resuscitation. 2015;94:67-72.

11. Callaway CW, Soar J, Aibiki M, et al. Part 4: Advanced Life Support: 2015 International Consensus on Cardiopulmonary Resuscitation and Emergency Cardiovascular Care Science with Treatment Recommendations. Circulation. 2015;132:S84-145.

12. Hunter $\mathrm{CL}$, Silvestri S, Ralls G, Bright S, Papa L. The sixth vital sign: prehospital end-tidal carbon dioxide predicts in-hospital mortality and metabolic disturbances. Am J Emerg Med. 2014:32:160-5.

13. Ahn A, Nasir A, Malik H, D'Orazi F, Parnia S. A pilot study examining the role of regional cerebral oxygen saturation monitoring as a marker of return of spontaneous circulation in shockable (VFNT) and non-shockable (PEA/ Asystole) causes of cardiac arrest. Resuscitation. 2013;84:1713-6.

14. Ito N, Nishiyama K, Callaway CW, et al. Noninvasive regional cerebral oxygen saturation for neurological prognostication of patients with out-of-hospital cardiac arrest: a prospective multicenter observational study. Resuscitation. 2014;85:778-84.

15. Chopra AS, Wong N, Ziegler CP, Morrison LJ. Systematic review and metaanalysis of hemodynamic-directed feedback during cardiopulmonary resuscitation in cardiac arrest. Resuscitation. 2016;101:102-7. 